Supplement of Biogeosciences, 15, 7435-7450, 2018

https://doi.org/10.5194/bg-15-7435-2018-supplement

(C) Author(s) 2018. This work is distributed under

the Creative Commons Attribution 4.0 License.

(c) (1)

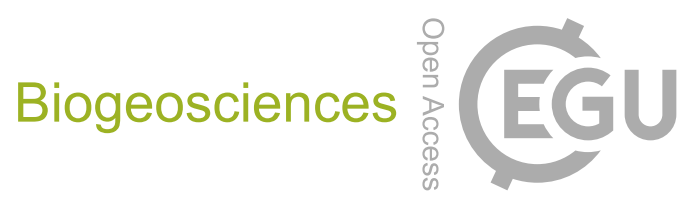

Supplement of

\title{
Fluvial organic carbon fluxes from oil palm plantations on tropical peat- land
}

Sarah Cook et al.

Correspondence to: Sarah Cook (sc606@le.ac.uk)

The copyright of individual parts of the supplement might differ from the CC BY 4.0 License. 


\section{Contents of this file}

1. Figures $\mathrm{S} 1$ to $\mathrm{S} 8$

2. Tables $\mathrm{S} 1$ to $\mathrm{S} 2$

3. Text S1to S2

\section{Introduction}

This supplementary material contains the rating curves established using salt dilution gauging for different points in the drainage networks of the Sebungan and Sabaju oil palm plantation. The goodness of fit metrics $\left(\mathrm{R}^{2}\right)$ and standard error of the estimate are also provided. The uncertainty associated with the dissolved organic carbon concentrations quantified using the TOC analyser is also provided along with the uncertainty in flux estimates as derived from Monte Carlo Simulations. The annual TOC fluxes for all monitored channels are also provided. Individual monitoring sites across the plantation estates are quoted as follows: Sebungan (SE 1, SE 2, SE 3, SE 4); Sabaju 1 (SA 1.1, SA 1.2, SA 1.3, SA 1.4), Sabaju 3 (SA 3.1, SA 3.5, SA 3.6); Sabaju 4 (SA 4.1, SA 4.2, SA 4.3, SA 4.4). 
Table S1. Rating curve equations, $\mathrm{R}^{2}$ and standard error of the estimate for all gauged channels. In all cases $y$ is discharge $\left(\mathrm{m}^{3} \mathrm{~s}^{-1}\right)$ and $x$ is stage $(\mathrm{m})$.

\begin{tabular}{cccc}
\hline Site & Line equation & $\mathbf{R}^{2}$ & Standard error estimate $\left(\mathbf{m}^{3} \mathbf{s}^{-1}\right)$ \\
\hline SE 1 & $y=0.1167 x^{3.3441}$ & 0.998 & 0.004 \\
SE 2 & $y=0.1289 x-0.0337$ & 0.979 & 0.001 \\
SE 3 & $y=0.0193 \ln (x)+0.0457$ & 0.956 & 0.002 \\
SE 4 & $y=0.0719 x^{1.5767}$ & 0.987 & 0.001 \\
\hline SA 1.2 & $y=0.0675 \ln (x)+0.1231$ & 0.996 & 0.001 \\
SA 1.3 & $y=0.1188 \ln (x)+0.14$ & 0.987 & 0.004 \\
SA 1.4 & $y=0.0341 e^{1.4756 x}$ & 0.954 & 0.007 \\
\hline SA 3.1 & $y=0.2699 x-0.0406$ & 0.928 & 0.026 \\
SA 3.5 & $y=0.0636 e^{1.4114 x}$ & 0.957 & 0.073 \\
SA 3.6 & $y=0.6878 x^{2.4519}$ & 0.978 & 0.018 \\
\hline SA 4.1 & $y=0.6554 x-0.4501$ & 0.988 & 0.015 \\
SA 4.2 & $y=0.0528 x^{3.959}$ & 0.920 & 0.040 \\
SA 4.3 & $y=0.3919 x-0.3112$ & 0.941 & 0.005 \\
SA 4.4 & $y=0.3446 x-0.1165$ & 0.924 & 0.020 \\
\hline
\end{tabular}


SE 1

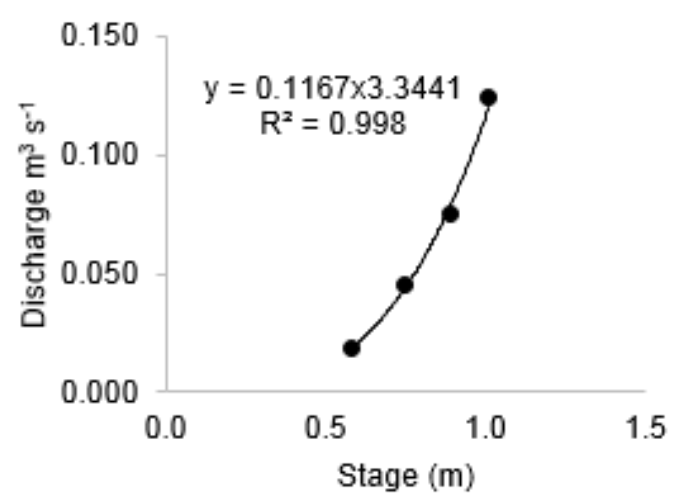

SE 3

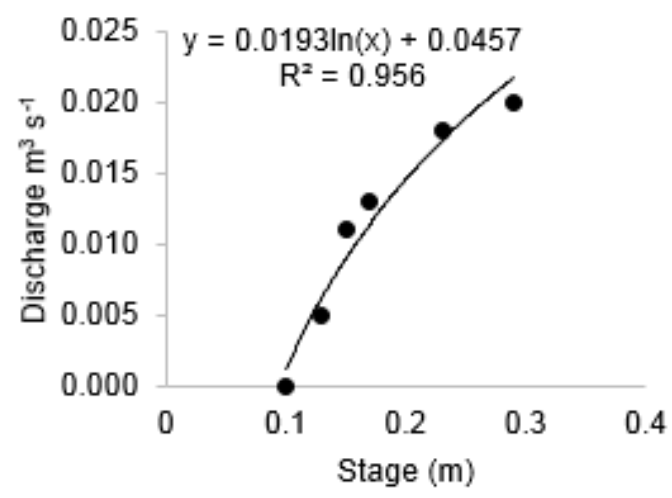

SA 1.2

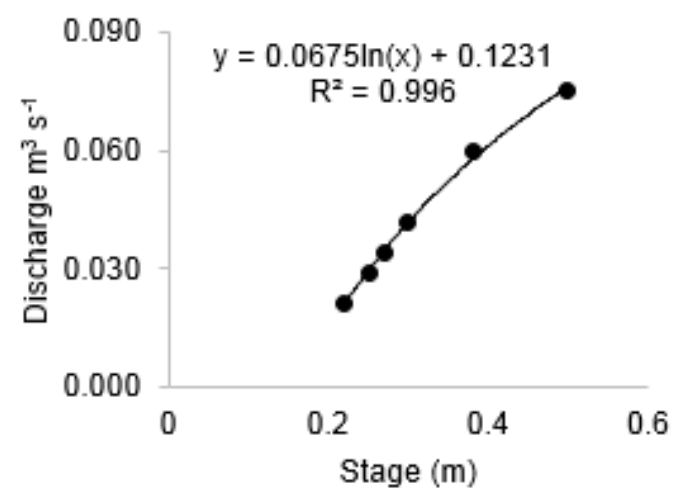

SE 2

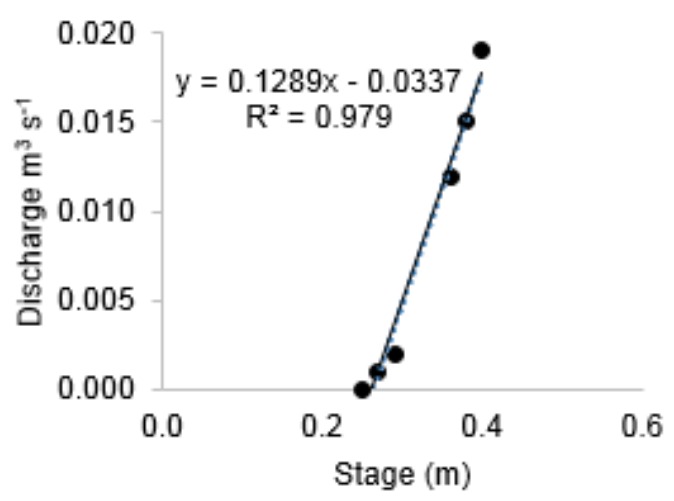

SE 4

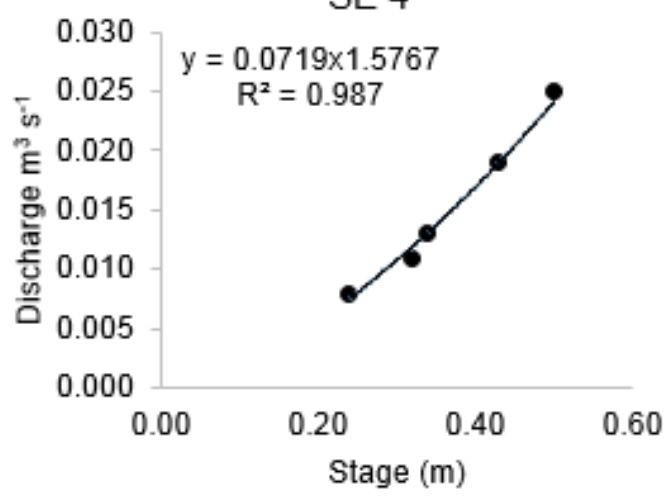

SA 1.3

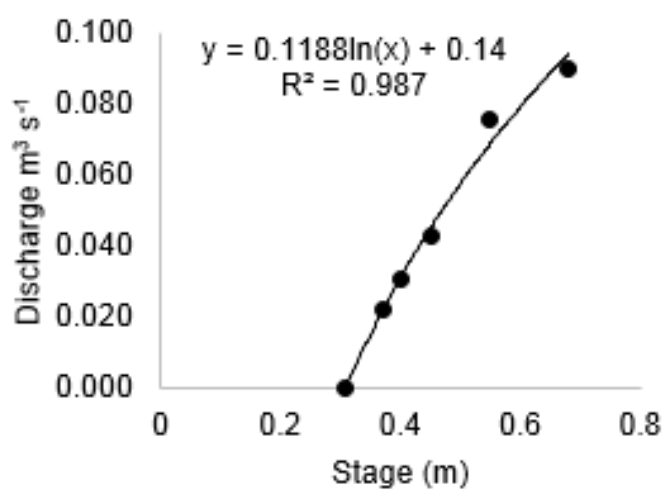

Figure S1. Stage-discharge relationships for drainage channel sites SE 1 to SA 1.3. The equation of best fit and the coefficient of determination $\left(\mathrm{R}^{2}\right)$ are also shown. 
SA 1.4
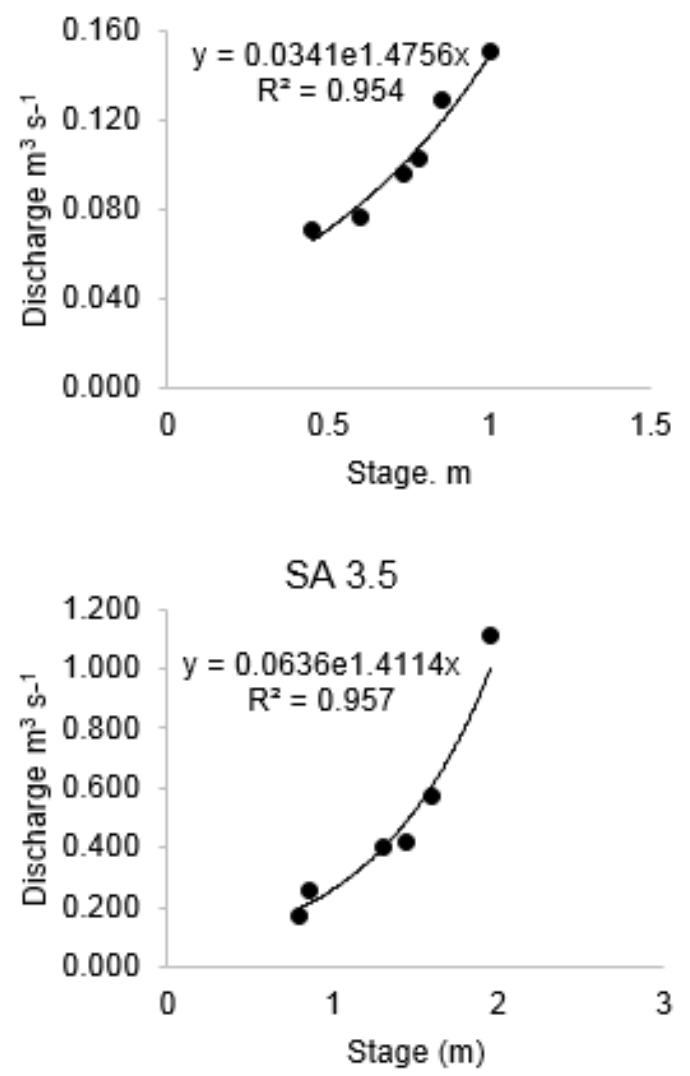

SA 4.1

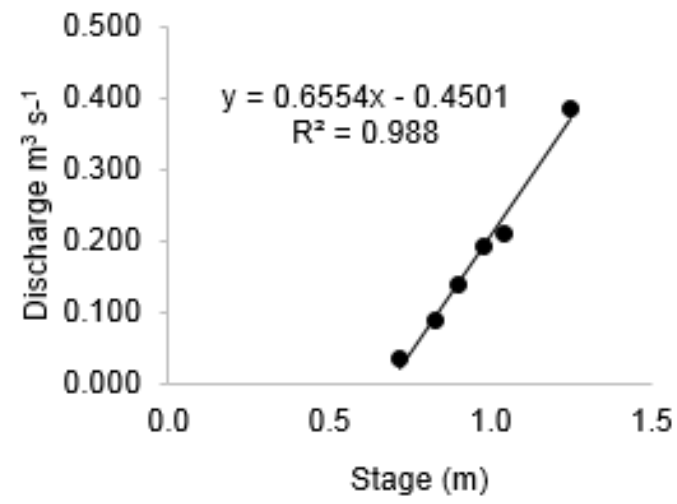

SA 3.1

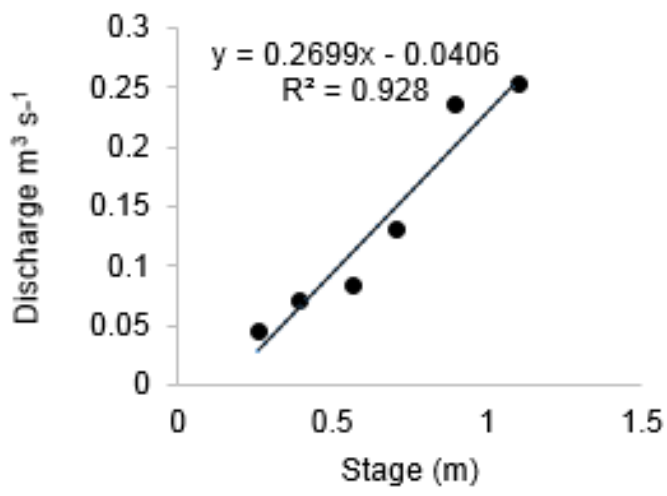

SA 3.6

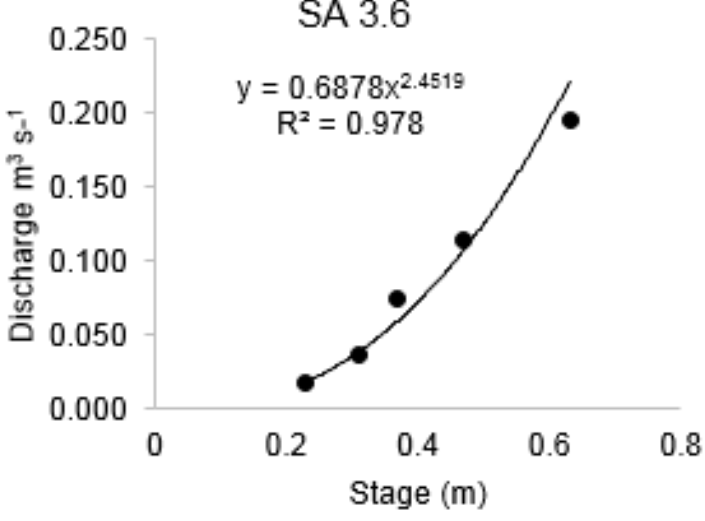

SA 4.2

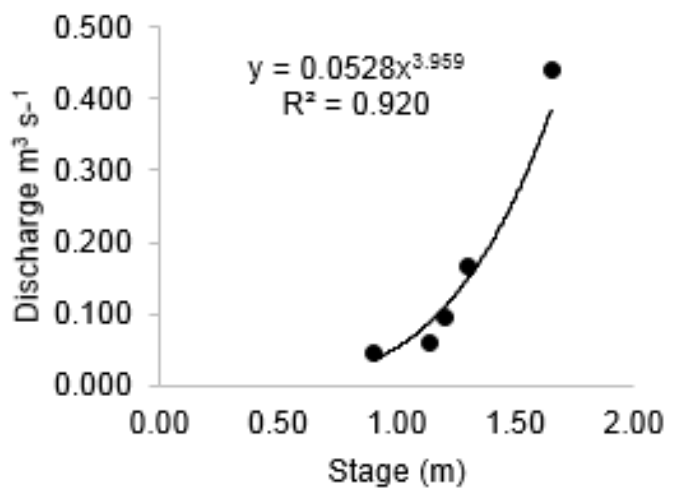

Figure S2. Stage-discharge relationships for drainage channel sites SA 1.4 to SA 4.2.

The equation of best fit and the coefficient of determination $\left(\mathrm{R}^{2}\right)$ are also shown. 

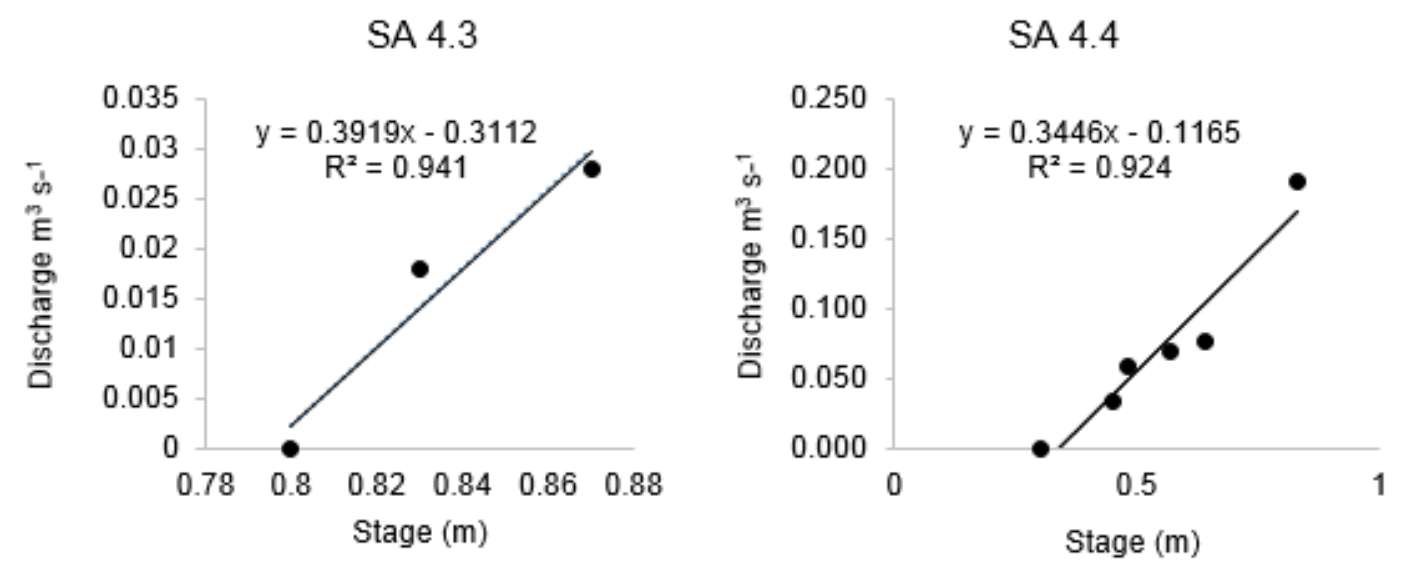

Figure S3. Stage-discharge relationships for drainage channel sites SA 4.3 and SA 4.4.

The equation of best fit and the coefficient of determination $\left(\mathrm{R}^{2}\right)$ are also shown. 


\section{Text S1}

Water samples were analysed on a on a Shimadzu Total Carbon (TOC) analyser, approximately 12 weeks after collection, and the DOC concentration determined using the non-purgeable organic carbon (NPOC) method. Details can be found in Cook et al. (2016). The standard error for TOC concentrations in the samples $\left(0.916 \mathrm{mg} \mathrm{C} \mathrm{L}^{-1}\right)$ was estimated by inverting the standard error of the estimate of the instrument response $(\varepsilon)$ in the calibration curve i.e. dividing $\varepsilon$ by the gradient in the calibration curve (concentration vs response) over a range of standard concentrations between 0 and $100 \mathrm{mg} \mathrm{C} \mathrm{L}^{-1}\left(r^{2}=\right.$ 0.998).

This error estimate is similar to the reported precision (5\%) associated with the TOC analyser at concentrations around $20 \mathrm{mg} \mathrm{L}^{-1}$ (Graneli et al. 1996; Bjorkvald et al. 2008; Shafer et al. 2010).

Cook et al. (2016) showed that there was no evidence of systematic storage-related DOC loss in the samples, supporting the use of cold storage for DOC preservation. 


\section{Text S2}

The uncertainty in flux estimates were derived using a Monte Carlo Simulation executed in Microsoft Excel using the @Risk (v7.5) software package (Palisade Corporation, USA). In the estimation of uncertainty about an expected value accounting for covariance is not required. In any case, the extent to which $Q_{i}$ and $C_{i}$ are correlated (although variable) is generally not significant. The uncertainty distribution in $R_{E}$ is shown in Figure S4.

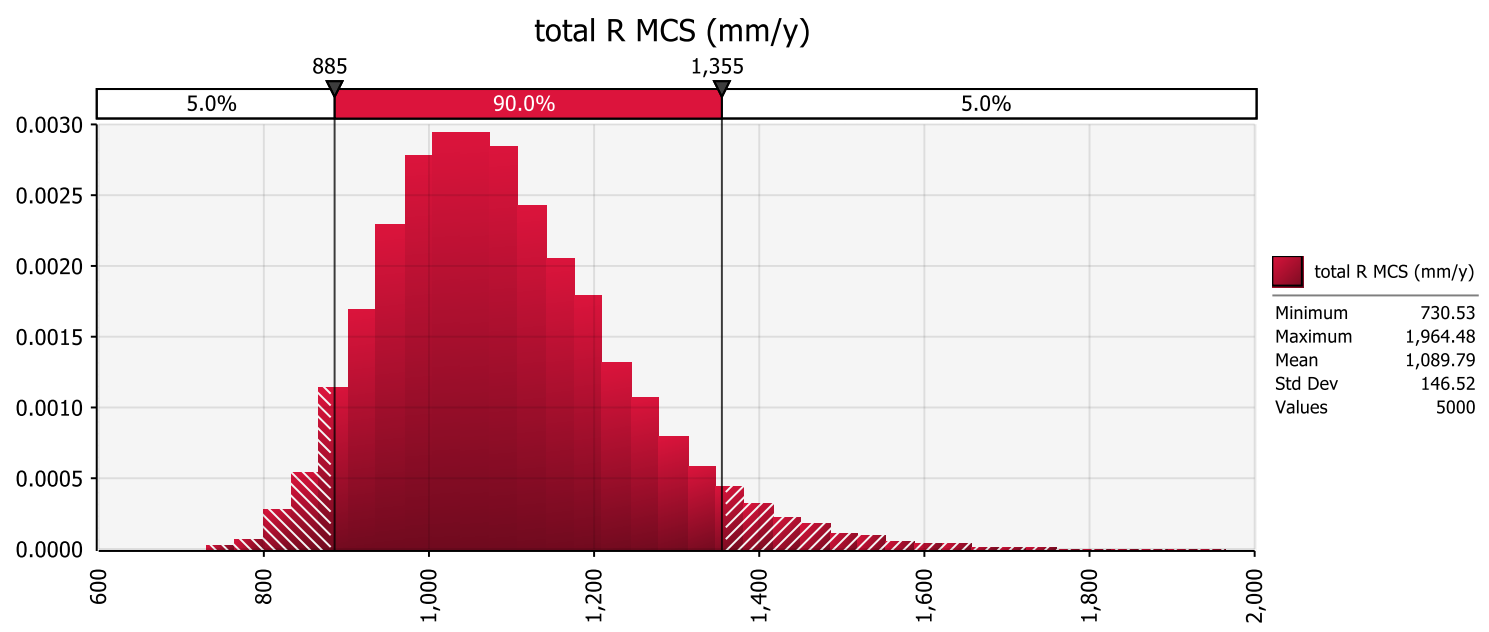

Figure S4. Uncertainty distribution in annual runoff for the study area $\left(\mathrm{mm} \mathrm{y}^{-1}\right)$. Dark shaded area shows the $90 \% \mathrm{CI}$. 
The uncertainty distribution in $J$ is shown in Figure S5 for SE1, SE2, SE3 and SE4; in Figure 6 for SA1.2, SA1.3, SA1.4 and SA3.1 and in Figure 7 for SA3.5-SA4.4.
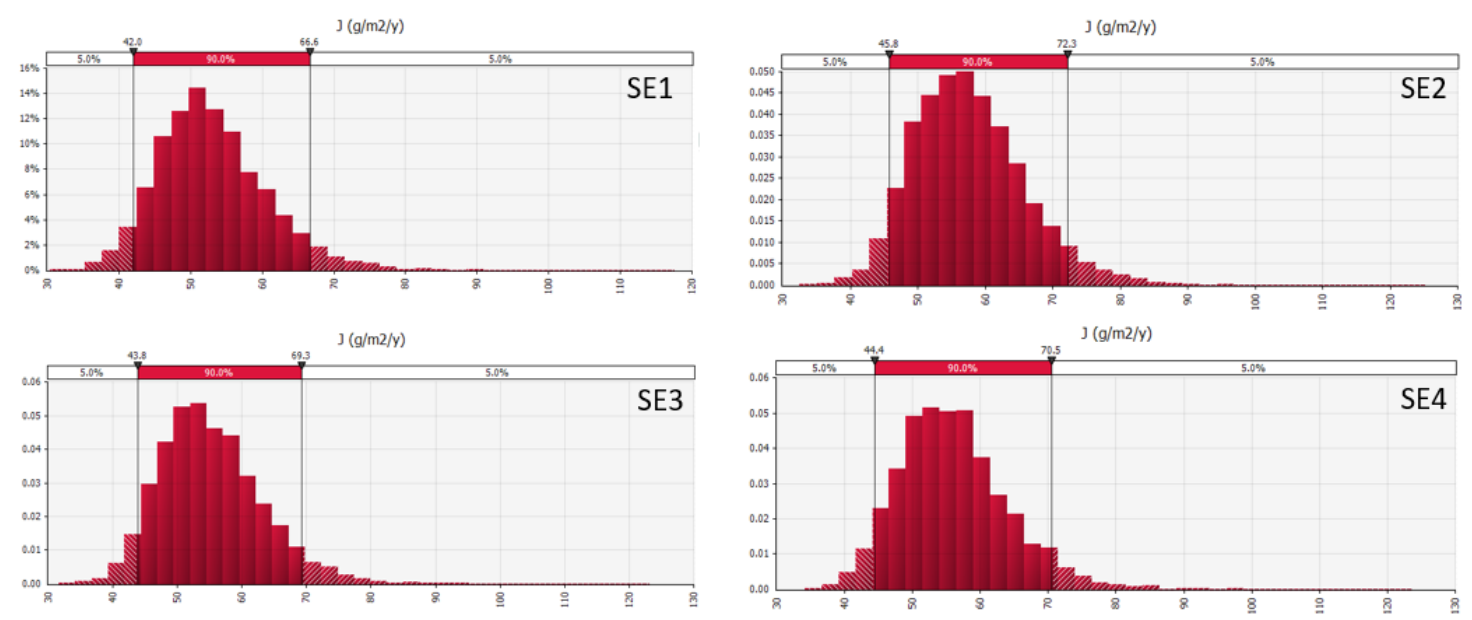

Figure S5. Uncertainty distributions in annual DOC flux estimates for the SE sites $\left(\mathrm{g} \mathrm{m}^{-2}\right.$ $\left.\mathrm{y}^{-1}\right)$. Dark shaded area shows the $90 \%$ CI. 

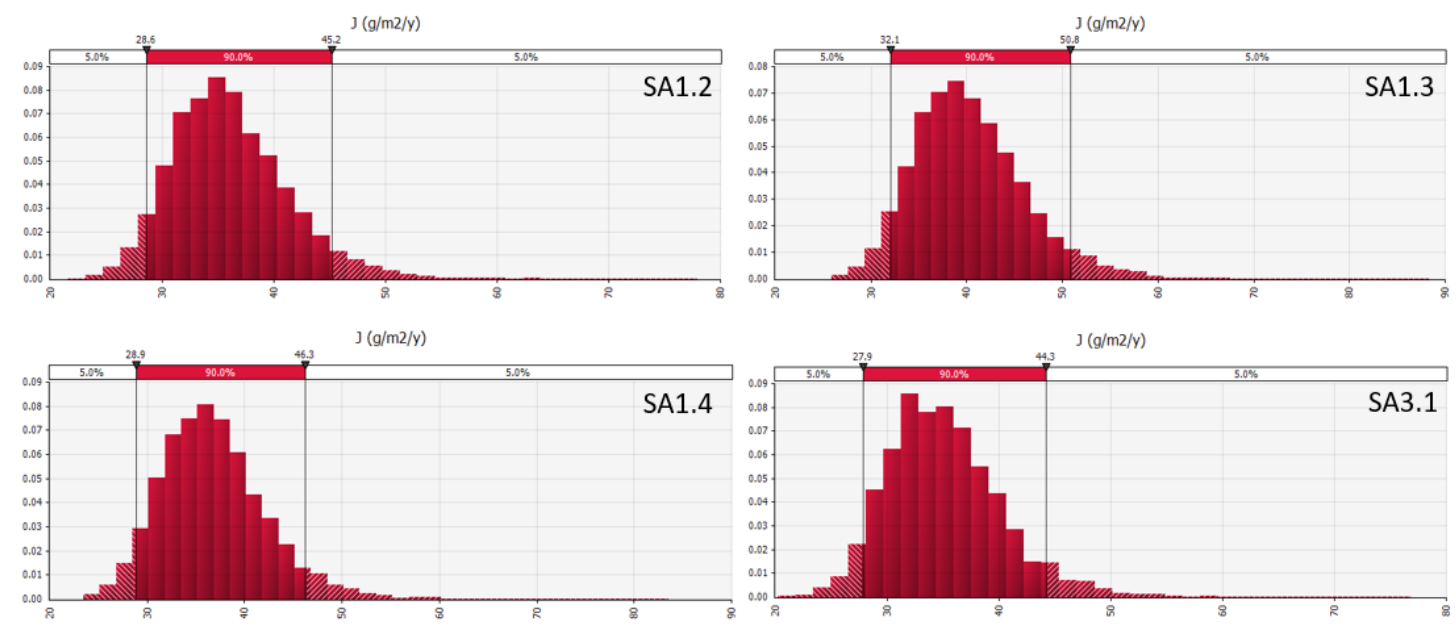

Figure S6. Uncertainty distributions in annual DOC flux estimates for the SA 1.2, 1.3, 1.4 and 3.1 sites $\left(\mathrm{g} \mathrm{m}^{-2} \mathrm{y}^{-1}\right)$. Dark shaded area shows the $90 \% \mathrm{CI}$. 

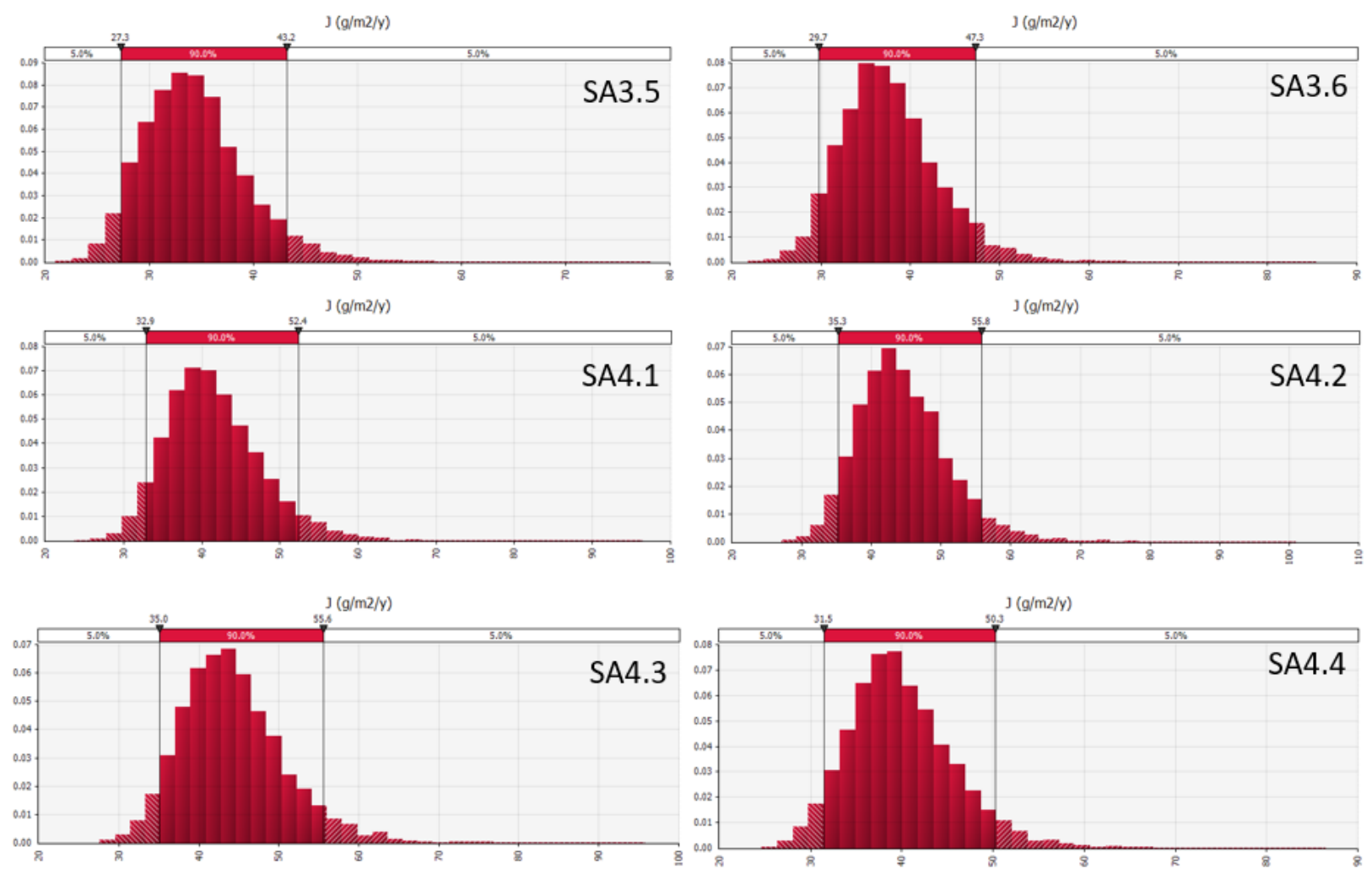

Figure S7. Uncertainty distributions in annual DOC flux estimates for the SA 3.5-4.4 sites $\left(\mathrm{g} \mathrm{m}^{-2} \mathrm{y}^{-1}\right)$. Dark shaded area shows the $90 \% \mathrm{CI}$. 
Table S2. Annual TOC fluxes, for the individual channels, \pm the $95 \%$ confidence interval (CI; standard error x 1.96) which encompasses the propagated error associated with uncertainty in the DOC concentration, discharge and annual runoff derived from the Monte Carlo Simulation

\begin{tabular}{|c|c|c|}
\hline & $\begin{array}{l}\text { Mean TOC flux } \\
\qquad\left(\mathrm{g} \mathrm{C} \mathrm{m}^{2} \mathrm{yr}^{-1}\right)\end{array}$ & $\begin{array}{l} \pm 95 \% \text { CI TOC flux } \\
\left(\mathrm{g} \mathrm{C} \mathrm{m}^{2} \mathrm{yr}^{-1}\right)\end{array}$ \\
\hline Site & & \\
\hline SE 1 & 53.02 & 14.99 \\
\hline SE 2 & 57.69 & 16.25 \\
\hline SE 3 & 55.22 & 15.64 \\
\hline SE 4 & 56.05 & 15.88 \\
\hline SA 1.2 & 36.05 & 10.15 \\
\hline SA 1.3 & 40.32 & 11.41 \\
\hline SA 1.4 & 36.75 & 10.49 \\
\hline SA 3.1 & 35.1 & 9.90 \\
\hline SA 3.5 & 34.37 & 9.70 \\
\hline SA 3.6 & 37.67 & 10.70 \\
\hline SA 4.1 & 41.59 & 11.86 \\
\hline SA 4.2 & 44.51 & 12.62 \\
\hline SA 4.3 & 44.22 & 12.52 \\
\hline SA 4.4 & 39.97 & 11.35 \\
\hline
\end{tabular}

